\title{
Isotachophoresis: the concepts of resolution, load capacity and separation efficiency. I: Theory
}

Citation for published version (APA):

Mikkers, F. E. P., Everaerts, F. M., \& Peek, J. A. F. (1979). Isotachophoresis: the concepts of resolution, load capacity and separation efficiency. I: Theory. Journal of Chromatography, 168(2), 293-315.

https://doi.org/10.1016/0021-9673(79)80001-1

DOI:

10.1016/0021-9673(79)80001-1

Document status and date:

Published: 01/01/1979

\section{Document Version:}

Publisher's PDF, also known as Version of Record (includes final page, issue and volume numbers)

\section{Please check the document version of this publication:}

- A submitted manuscript is the version of the article upon submission and before peer-review. There can be important differences between the submitted version and the official published version of record. People interested in the research are advised to contact the author for the final version of the publication, or visit the $\mathrm{DOI}$ to the publisher's website.

- The final author version and the galley proof are versions of the publication after peer review.

- The final published version features the final layout of the paper including the volume, issue and page numbers.

Link to publication

\section{General rights}

Copyright and moral rights for the publications made accessible in the public portal are retained by the authors and/or other copyright owners and it is a condition of accessing publications that users recognise and abide by the legal requirements associated with these rights.

- Users may download and print one copy of any publication from the public portal for the purpose of private study or research.

- You may not further distribute the material or use it for any profit-making activity or commercial gain

- You may freely distribute the URL identifying the publication in the public portal.

If the publication is distributed under the terms of Article 25fa of the Dutch Copyright Act, indicated by the "Taverne" license above, please follow below link for the End User Agreement:

www.tue.nl/taverne

Take down policy

If you believe that this document breaches copyright please contact us at:

openaccess@tue.nl

providing details and we will investigate your claim. 
(C) Elsevier Scientific Publishing Company, Amsterdam - Printed in The Netherlands

CHROM. 11,345

ISOTACHOPHORESIS: THE CONCEPTS OF RESOLUTION, LOAD CAPACITY AND SEPARATION EFFICIENCY

\section{THEORY}

F. E. P. MIKKERS, F. M. EVERAERTS and J. A. F. PEEK*

Department of Instrumental Analysis, Eindhoven University of Technology, Eindhoven (The Netherlands)

(First received February 14th, 1978; revised manuscript received June 15th, 1978)

\section{SUMMARY}

The fundamental definitions of resolution and separability in isotachophoresis are given and extensively discussed. The resolution of a constituent is given as its fractional separated amount and can vary between zero and unity. The steady-state configuration is characterized by resolution values of unity and/or zero and is determined by both the leading electrolyte and the sample. The separability of two constituents depends largely on their physico-chemical characteristics and the time allowed for resolution.

The isotachophoretic separation process is elucidated using a transient-state model for monovalent, weakly ionic constituents. The influence of operational parameters, i.e., $\mathrm{pH}$, electrical driving current, sample load and counter constituent, on the separation process is described in terms of resolution time, detection time and load capacity. The efficiency of the separation process is given by the dimensionless separation number.

It is shown that optimization procedures are governed by three rationales: the electrical driving current, the common counter constituent and the $\mathrm{pH}$. Of these, only the electrical driving current has no influence on the separation efficiency and load capacity. For anionic separations a low $\mathrm{pH}$ of both sample and leading electrolyte favours resolution. When dealing with cationic scparations a high $\mathrm{pH}$ is preferable. The counter constituent should have a low mobility and the electrical driving current should be maximized.

\section{INTRODUCTION}

In isotachophoresis a steady-state configuration is obtained as the result of a separation process that proceeds according to the moving boundary principle ${ }^{1,2}$. Although this separation process is a transient state, it is governed by the same regulating function concept as the steady state ${ }^{2}$. A quantitative and qualitative descrip-

\footnotetext{
* Present address: Philips Research Laboratories, Eindhoven, The Netherlands.
} 
tion of the transient state provides information on the time needed for an isotachophoretic separation ${ }^{3}$. Moreover, such a description requires the definition of resolution and separability in isotachophoresis and shows the results that can be expected from optimization procedures.

In this paper we present a relatively simple model, dealing with the theoretical concepts of the separation process, resolution, separability and separation efficiency. The practical implications concerning resolution time, detection time and load capacity are deduced. Optimization procedures by means of operational conditions and electrolyte systems are given. In a forthcoming paper the practical evaluation will be presented.

\section{GENERAL EQUATIONS AND DEFINITIONS}

In electrophoresis the migration velocity, $v$, of a constituent $i$ is given by the product of effective mobility $\vec{m}_{i}$ and the local electrical field strength, $E$ :

$$
v_{i}=\bar{m}_{i} E
$$

The electrical field strength is vectorial so the effective mobilities can be taken as signed quantities, positive for constituents that migrate in a cathodic direction and negative for those migrating anodically. As a constituent may consist of several forms of sub-species in rapid equilibrium, the effective mobility represents an average ensemble. Not dealing with constituents consisting of both positively and negatively charged subspecies in equilibrium, we can take concentrations with a sign corresponding to the charge of the sub-species. Thus the total constituent concentration, $\bar{c}_{i}$, is given by the summation of all of the sub-species concentrations, $c_{n}$ :

$$
\bar{c}_{i}=\sum_{n} c_{n}
$$

Following the mobility concept of Tiselius ${ }^{4}$, the effective mobility is given by

$$
\bar{m}_{i}=\sum_{n} \frac{c_{n} m_{n}}{\bar{c}_{i}}
$$

where $m_{n}$ is the ionic mobility of the sub-species. In dissociation equilibria the effective mobility can be evaluated using the degree of dissociation, $\alpha$ :

$$
\bar{m}_{i}=\sum_{n} \alpha_{n} m_{n}
$$

The degree of dissociation can be calculated once the equilibrium constant, $K$, for the sub-species and the $\mathrm{pH}$ of the solution are known. For a restricted $\mathrm{pH}$ range a very useful relationship has been given by Hasselbalch ${ }^{5}$ :

$$
\mathrm{pH}=\mathrm{p} K \perp \log \left(\frac{1}{c}-1\right)
$$

where $\mathrm{p} K$ is the negative logarithm of the protolysis constant; the positive sign holds for cationic sub-species and the negative sign for anionic sub-species. 
All electrophoretic processes are essentially charge-transport processes that obey Ohm's law. In electrophoresis this law is most conveniently expressed in terms of electrical current density, $J$, specific conductance, $\kappa$, and electrical field strength:

$$
J=\kappa E
$$

The specific conductance is given by the individual constituent contributions:

$$
\kappa=F \sum_{i} \bar{c}_{i} \bar{n}_{i}
$$

where $F$ is the the Faraday constant.

The equation of continuity states for any electrophoretic process ${ }^{6}$ that

$$
\frac{\partial}{\partial t} \cdot \bar{c}_{i}=-\frac{\partial}{\partial x}\left(\frac{\partial}{\partial x} D_{i} \bar{c}_{i}-v_{i} \bar{c}_{i}\right)
$$

where $t$ and $x$ are time and place coordinates, respectively, and $D$ is the diffusion coefficient. Neglecting diffusional dispersion we can apply eqn. 8 for each constituent and the overall summation of the constituents gives

$$
\frac{\partial}{\partial t} \sum_{i} \bar{c}_{i}=\frac{\partial}{\partial x} \cdot E \sum_{i} \bar{m}_{i} \bar{c}_{i}
$$

In combination with the specific conductance (eqn. 7) and the modified Ohm's iaw (eqn. 6), it follows that

$$
\frac{\partial}{\partial t} \sum_{i} \bar{c}_{i}=0 \text { or } \sum_{i} \bar{c}_{i}=\text { constant }
$$

For monovalent weakly ionic constituents, eqn. 8 can be written as

$$
\frac{\partial}{\partial t} \cdot \bar{c}_{i}=\frac{\partial}{\partial x} \cdot E m_{i} c_{i}
$$

where $m_{i}$ and $c_{i}$ are the mobility and the concentration of the charged species $i$. Division by $m_{i}$ and application of the resulting relationship for each constituent and overall summation gives

$$
\frac{\partial}{\partial t} \sum_{i} \frac{\bar{c}_{i}}{m_{i}}=\frac{\partial}{\partial x} \cdot E \sum_{i} c_{i}
$$

Electroneutrality, however, demands $\frac{\Sigma}{i} c_{i}=0$, so

$$
\frac{\partial}{\partial t} \sum_{i} \frac{\bar{c}_{i}}{m_{i}}=0 \quad \text { or } \quad \sum_{i} \frac{\bar{c}_{i}}{m_{i}}=\text { constant }
$$

Eqn. 13 is well known as the Kohlrausch regulating function ${ }^{7}$.

In an electrophoretic system different zones can be present, in which a zone is defined ${ }^{8}$ as a homogeneous solution demarcated by moving and/or stationary boundaries. We can apply the continuity principle (eqn. 8) to a boundary (Fig. 1) and derive the general form of the moving boundary equation ${ }^{9}$ :

$$
\bar{m}_{i}^{K} \bar{c}_{i}^{K} E^{K}-\bar{m}_{i}^{K+1} \bar{c}_{i}^{K+1} E^{K+1}=v^{K / K+1}\left(\bar{c}_{i}^{K}-\bar{c}_{i}^{K+1}\right)
$$




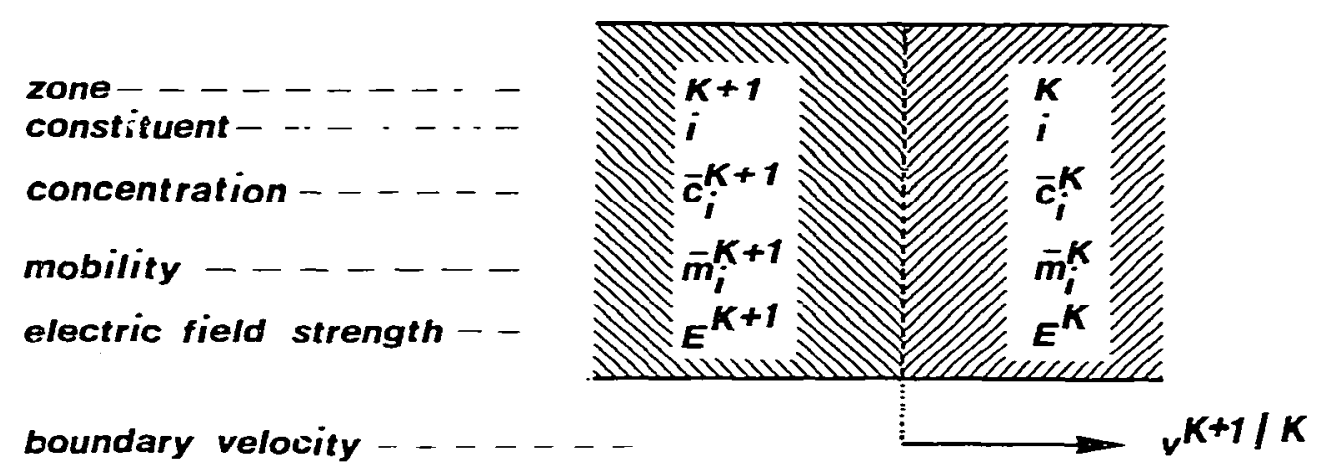

Fig. 1. A moving boundary.

where $v^{K / K} \div 1$ represents the drift velocity of the separating boundary between the zones $K$ and $K+1$. In the case of a stationary boundary, the boundary velocity is zero and eqn. 14 reduces to

$$
\frac{\bar{m}_{i}^{K+1} \bar{c}_{i}^{K+1}}{\bar{m}_{i}^{K} \bar{c}_{i}^{K}}=\frac{E^{K}}{E^{K+1}}=\text { constant }
$$

From eqn. 15 it follows directly that for monovalent weak and strong electrolytes all ionic subspecies are diluted or concentrated over a stationary boundary to the same extent, because

$$
\frac{c_{i}^{K+1}}{c_{i}^{K}}=\text { constant }
$$

In isotachophoresis sample constituents migrate in a stacked configuration, steady state, between a leading ionic constituent of high effective mobility and a terminating constituent of low effective mobility. From the moving boundary equation (eqn. 9) it follows directly that, in a separation compartment of uniform dimensions at constant electrical driving current, all boundary velocities within the isotachophoretic framework are equal and constant. Accordingly to Joule's law, heat generation will occur, resulting in different temperature regimes that are moving or stationary. In order to reduce the effects of temperature, relative mobilities, $r$, can be introduced. Obviously the leading constituent, $L$, provides the best reference mobility:

$$
r_{i}=\frac{m_{i}}{m_{L}}
$$

Moreover, as in most isotachophoretic separations, only one counter constituent, $C$, will be present, the reduced mobility, $k$, can be introduced:

$$
k_{i}=\frac{1-r_{c}}{r_{i}-r_{c}}
$$

Using the derived equations it is possible to calculate all dynamic parameters of analytical importance. Moreover, model considerations can be extended to moving boundary electrophoresis as well as to zone electrophoresis. 


\section{The criterion for separation}

As in all differential migration methods, the criterion for separation in isotachophoresis depends simply on the fact that two ionogenic constituents will separate whenever their migration rates in the mixed state are different. For two constituents $i$ and $j$, this means that according to eqn. 1 their effective mobilities in the mixed state must be different:

$$
\frac{\bar{m}_{i}}{\bar{m}_{j}} \neq 1
$$

When the effective mobility of $i$ is higher than that of $j$ the latter constituent will migrate behind the former. Consequently, two monovalent weakly anionic constituents will fail to separate when the $\mathrm{pH}$ of the mixed state, $\mathrm{pH}^{M O}$, is given by

$$
\mathrm{pH}^{M}=\mathrm{pH}^{M o}=\mathrm{pK}_{j}+\log \left(\frac{1-\frac{r_{j} K_{j}}{r_{i} K_{i}}}{\frac{r_{j}}{r_{i}}-1}\right)
$$

where $K_{i}$ and $K_{j}$ are the protolysis constants for the sub-species of the constituents $i$ and $j$. When the more mobile constituent has a higher protolysis constant, we are dealing with a "straight" pair of constituents; when the more mobile constituent has a lower protolysis constant, we have a "reversed" pair of constituents, for which the separation configuration is a function of the $\mathrm{pH}$. Possible configurations are illustrated in Fig. 2. For cationic species equivalent relationships can be obtained.

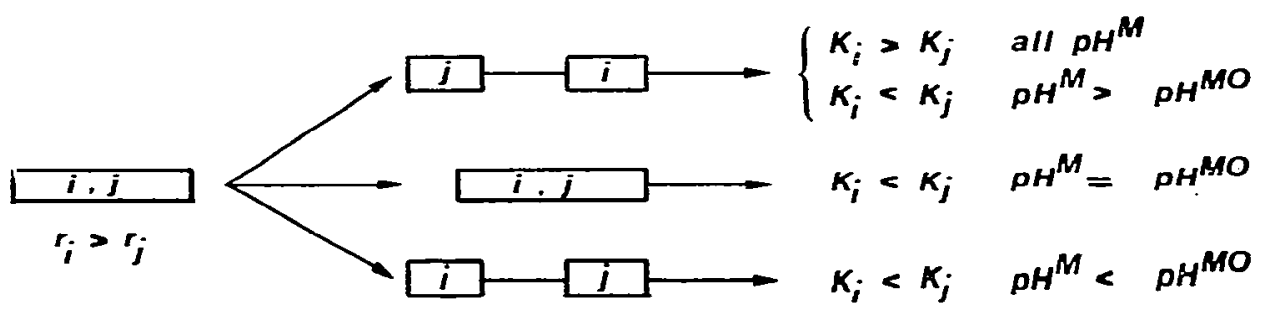

Fig. 2. Possible migration configurations for anionic constituents.

\section{RESOLUTION}

Once the criterion for separation has been satisfied, the time needed for resolution becomes important. When a constituent zone contains all of the sampled amount, resolution has been obtained for that constituent. We therefore define the resolution, $R$, as the separated fractional amount of the constituent:

$$
R_{i}=\frac{\text { separated amount of } i}{\text { sampled amount of } i}
$$

From this definition, it follows that during the separation process the resolution increases from zero to its maximal value, unity. Constituents that fail to separate remain at zero resolution and can be termed ideally mixed zones ${ }^{10}$. 
Complete separation of a sample requires the resolution values of all constituents of interest to be unity. Maximal speed of separation is obtained whenever the resolution rate, $\partial / \partial t \cdot R_{i}$, is optimized during the separation process. As expected, the resolution and its time derivatives are complex functions of the constituents involved and the driving forces applied. Moreover, the mathematical intricacy involved in calculating optimal process variables increases rapidly with increasing number and complexity of the sample constituents. For strong electrolytes relevant mathematical formulations have been publishcd ${ }^{3,9}$, but most separations nowadays concern weak electrolytes. In this case dissociation equilibria, and therefore a proper choice of $\mathrm{pH}$, are tools in the control and optimization of the separation process ${ }^{2}$. When dealing with complex formation, association equilibria should be involved. Others $^{11}$ have suggested that the difference in migration rates, e.g., $v_{i}-v_{j}$, is of decisive importance in separation. However, in isotachophoresis and moving boundary electrophoresis this does not apply, and in these instances it is more beneficial to optimize the ratio of the migration rates, e.g., $v_{i} / v_{j}$. Whereas the velocity difference will reach a maximal value as a function of $\mathrm{pH}^{11}$, the ratio shows no such optimum ${ }^{12}$. As the local electrical field strength for both constituents will be the same, it follows directly that eqn. 19 must be maximized or minimized, depending on the migration configuration (Fig. 2). Introducing equilibrium constants and ionic mobilities it follows that in anionic separations the lowest $\mathrm{pH}$ will give the better mobility ratio, and vice versa for cationic separation $\mathrm{s}^{12,13}$. It should be emphasized, however, that $\mathrm{pH}$ extremes have only limited experimental applicability and that practical considerations often govern the proper choice of $\mathrm{pH}$. Moreover, a low numerical value of the effective mobility will induce a high electrical field strength in order to obtain an appreciable migration rate and other elektrokinetic effects may then prevail.

Steady state

A unique feature of isotachophoresis is that, once the separation process has been completed, all electrophoretic parameters remain constant with time. Assuming a uniform current density, all sample constituents within the leading-terminating framework will migrate at identical speed. Moreover, at constant current density local migration rates will be constant. In this steady state, resolution values of stacked constituents will be either unity or zero. cussed ${ }^{2}$.

The basic features of steady-state configurations have been extensively dis-

\section{THE SEPARATION PROCESS}

The applicability of the above equations and definitions and the resulting implications are best illustrated by using a relatively simple two-component sample. We shall deal with the case where all constitucnts involved are monovalent weak electrolytes. Although essentially immaterial, we shall consider a separation compartment of uniform dimensions at a constant electrical driving current and a constant temperature. The separation process and some relevant information are given in Fig. 3.

It should be emphasized that within the separator three different regions are present and each has its own regulating behaviour. The regulating functions (eqns. 


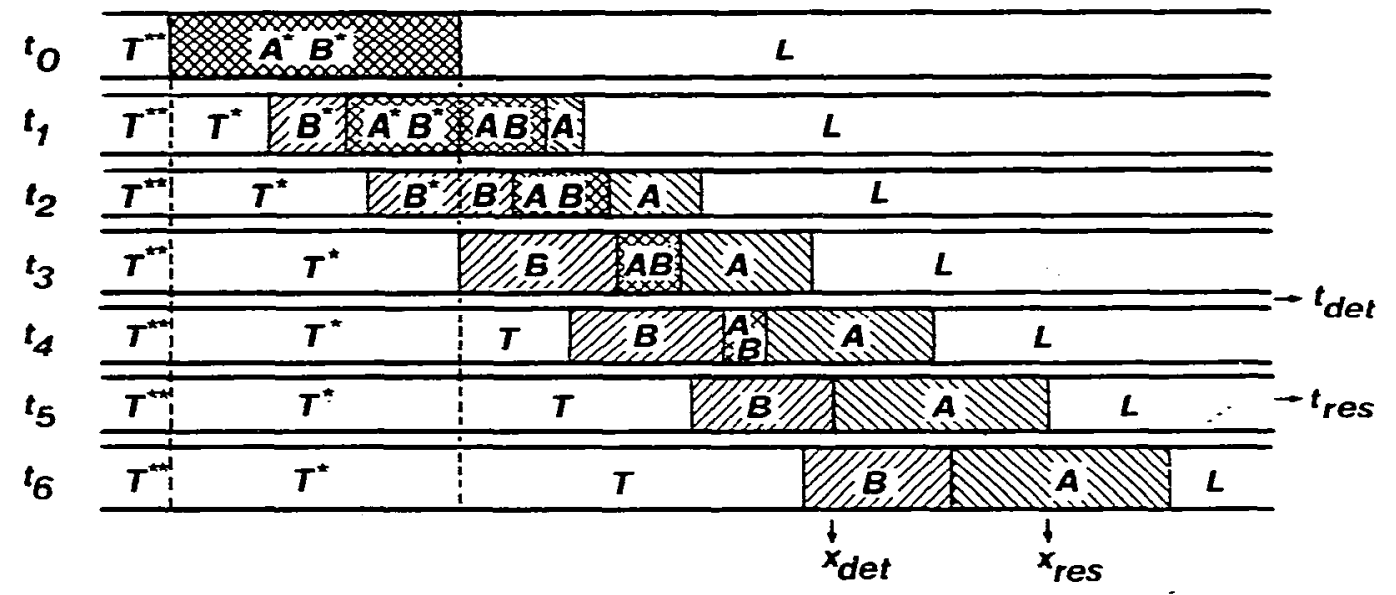

$$
\vdash \text { sampling } \rightarrow \rightarrow-\text { separation compartment }
$$

Fig. 3. Process of separation of two constituents. In the initial situation, $t_{0}$, the sampling compartment has been filled with a homogeneous mixture of the two sample constituents $A$ and $B$. The separation compartment contains the leading constituent $L$ and the terminating compartment is filled with the terminating constituent $T$. A counter constituent $C$, to preserve electroneutrality, is common to both sample constituents, the leading and the terminating constituents. Electrolyte changes in the electrode compartments, temperature and activity effects are neglected. Each compartment may have its own regulating function, due to the initial composition of the electrolytes. Starting from $t_{0}$ the separation of the sample will occur according to the moving boundary principle. All zone characteristics are, as long as they exist, constant with time. At different times several moving boundaries can be present: $A / L, A B / A, B / A B, B / A, T / B, B^{*} / A B^{*}, T^{*} / B^{*}$. Boundary velocities are given by local conditions. The sampling compartment causes the stationary boundaries: $A B^{*} / A B, B^{*} / B, T^{*} / T, T^{* *} / T$. At $t_{3}$ the sample is leaving the sampling compartment and from this time on the total zone length of the sample zone will be constant. The properties of the mixed zone in the separation compartment will be in agreement with the local regulating function and the nature of the sample. At $t_{5}$ resolution is obtained and from this moment the individual zone lengths will be constant. It follows that both of the constituents have been concentrated. Resolution was obtained at $t_{\mathrm{rcs}}$ with a resolution length of $x_{\text {res. }}$. Detection could have been started at $t_{\mathrm{det}}$ with the detection system located at $x_{\mathrm{der}}$.

10 and 13) are the mathematicai expression of this regulating behaviour and locally they cannot be overruled by the electrophoretic process ${ }^{7}$. All changes in electrophoretic parameters, e.g., concentration, $\mathrm{pH}$ and conductance, will be in agreement with the local regulating function. Applying eqn. 16 to the stationary boundary between the scparation and the sampling compartment it follows that

$$
\Psi=\frac{c_{B}^{M *}}{c_{A}^{M *}}=\frac{c_{B}^{M}}{c_{A}^{M}}=\text { constant }
$$

Hence, the sampling ratio, $\%$, for the charged sub-species is invariable. Taking the leading electrolyte as a frame of reference, the regulating functions (eqns. 10 and 13) will result in

$$
\bar{c}_{L}^{L}+\bar{c}_{C}^{L}=\bar{c}_{A}^{M}+\bar{c}_{B}^{M}+\bar{c}_{C}^{M}
$$


and

$$
\frac{\bar{c}_{L}^{L}}{r_{L}}+\frac{\bar{c}_{C}^{L}}{r_{C}}=\frac{\bar{c}_{A}^{M}}{r_{A}}+\frac{\bar{c}_{B}^{M}}{r_{B}}+\frac{\bar{c}_{C}^{M}}{r_{C}}
$$

where $C$ is the counter constituent common to all constituents to be separated. The equilibrium relationships (eqn. 5) and electroneutrality imply that

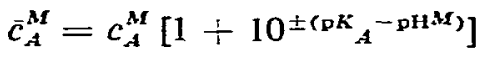

$$
\begin{aligned}
& \vec{c}_{B}^{M}=\varphi c_{A}^{M}\left[1+10^{ \pm\left(p K_{B}-\mathrm{pH}^{M}\right)}\right]
\end{aligned}
$$

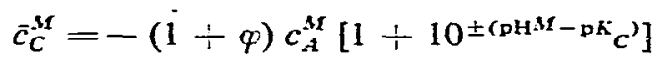

Combining equs. 23,24 and 25 we obtain

$$
\bar{c}_{L}^{L}+\bar{c}_{C}^{L}=c_{A}^{M}\left[\frac{1}{\alpha_{A}^{M}} \div \frac{q}{\alpha_{B}^{M}}-\frac{(1+\varphi)}{\alpha_{C}^{M}}\right]
$$

and

$$
c_{L}^{L}\left(1-r_{C}\right)=c_{A}^{31}\left[\frac{r_{A}-r_{C}}{r_{A} c_{A}^{3 /}}+\frac{q\left(r_{B}-r_{C}\right)}{r_{B} \alpha_{B}^{3 r}}\right]
$$

We now introduce the relative leading concentration

$$
\underline{o}=\frac{\bar{c}_{C}^{L}}{\bar{c}_{L}^{L}}
$$

and the reduced mobility. Elimination of $c_{A}^{M}$ gives a quadratic equation for the proton concentration in the mixed zone. Only one root will have physical significance.

$$
a \cdot 10^{2 \mathrm{pH}^{\mathrm{N}}}+b \cdot 10^{\mathrm{pH}}+c=0
$$

The constants for the equation are given in Table $\mathbf{I}$.

\section{TABLE I}

DYNAMIC CONSTANTS FOR THE pH OF THE MIXED ZONE (EQN. 28)

$$
\begin{aligned}
& \text { Anionic constituents } \\
& \text { Cationic constituents } \\
& a=10^{-p} \kappa_{c}(1+p) \\
& a=10^{-p K_{A}}\left(\frac{1+g}{r_{A} k_{A}}-1\right)+p \cdot 10^{-p K_{B}}\left(\frac{1+Q}{r_{B} k_{B}}-1\right) \\
& b=(1 \div \varrho)\left(\frac{1}{r_{A} k_{A}} \div \frac{\varphi}{r_{B} k_{B}}\right) \\
& b=(1 \div \underline{g})\left(\frac{1}{r_{A} k_{A}}+\frac{\varphi}{r_{B} k_{B}}\right) \\
& c=10^{D K} K_{A}\left(\frac{1+g}{r_{A} k_{A}}-1\right)+\varphi \cdot 10^{D K_{B}}\left(\frac{1+g}{r_{B} k_{B}}-1\right) \quad c=10^{\rho K} c(1+\varphi)
\end{aligned}
$$


Once the $\mathrm{pH}$ in the mixed zone has been calculated, all dynamic process variables can be calculated by using eqns. 1-27. Moreover, steady-state configurations are obtained by the introduction of zero or infinite sampling ratios. Moving boundary experiments can be simulated by introduction of a high load of sample. Computerization allows multiple calculations of all dynamic process variables ${ }^{13}$.

\section{The $p H$ of the mixed zone}

As the criterion for separation has to be satisfied and the ratio of effective constituent mobilities must be optimized, the $\mathrm{pH}$ of the mixed zone is of decisive importance. According to eqn. 28, this $\mathrm{pH}$ is influenced by the physico-chemical characteristics of the species to be separated and the counter constituent, by the sampling ratio, $q$, and the relative leading concentration, $\varrho$. The lașt parameter is closely related to the $\mathrm{pH}$ of the leading electrolyte and the former to the $\mathrm{pH}$ of the sample. We shall consider anionic separations, but equivalent relationships and conclusions can be made for cationic separations.

In isotachophoresis the leading constituent must have a high effective mobility, so strong ionic species like chloride are commonly used ${ }^{2}$. In this instance it foliows that

$$
-\infty<D=-\frac{1}{c_{c}^{L}}<-1
$$

At $\varrho=-1$ the counter constituent is used far below its $\mathrm{p} K$ value and it behaves like a strongly ionic species. In this event the leading electrolyte has no buffering capacity. At $\varrho=-2$ the counter constituent is used at its $\mathrm{p} K$ value, $\mathrm{pH} \mathrm{H}^{t}=\mathrm{p} K_{C}$, and therefore it exhibits its full buffering capabilities. High negative values for the relative leading concentration again imply low buffering. Moreover, the concentration of the counter constituent will be high in comparison with that of the leading constituent, which can be favourable in complex formation. It is easily shown that for increasing $\mathrm{pH}^{L}-\mathrm{p} K_{i, j}$ i.e., the constituents to be separated are only partially dissociated at the $\mathrm{pH}$ of the leading electrolyte, $\mathrm{pH}^{M}-\mathrm{pH}^{L}$ will increase. Constituents that are completely ionized at the $\mathrm{pH}$ of the leading electrolyte will induce only a slight elevation of $\mathrm{pH}^{M}$ and therefore will be separated as strong electrolytes. Counter constituents with a low $\mathrm{p} K$ value in comparison with the $\mathrm{pH}$ of the leading electrolyte show a tendency to diminish this increase in $\mathrm{pH}^{M}$. When the leading constituent is a strongly ionic species the $\mathrm{pH}$ of any following zone will be higher than the pH of the leading zone. If, however, a weak constituent is chosen as the leading constituent negative $\mathrm{pH}$ steps can occur under appropriate conditions ${ }^{2}$.

Obviously, problems in separation generally occur when both the $\mathrm{p} K$ values and the ionic mobilities of the constituents show only slight differences. An example of such a pair is given in Fig. 4. When the more mobile constituent has the higher dissociation constant (a straight pair), the criterion for separation will always be satisfied (Fig. 4a). Optimization in this instance is straightforward: low $\mathrm{pH}^{L}$ and low $\mathrm{p} K_{c}$. However, when the more mobile constituent has the lower equilibrium constant (a reversed pair), the criterion for separation need not always be satisfied. It will depend on the proper choice of $\mathrm{pH}^{L}$ and $\mathrm{p} K_{c}$ whether the critical $\mathrm{pH}, \mathrm{pH}^{\text {so }}$ (as indicated in Fig. $4 \mathrm{a}$ with an asterisk) will be obtained. 

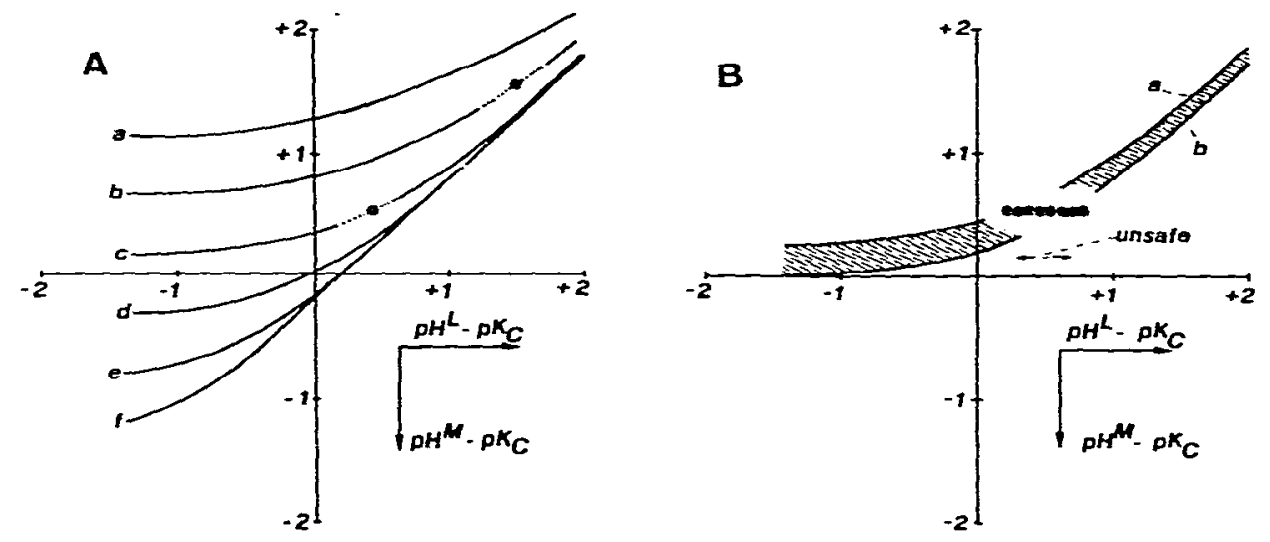

Fig. 4. (A) Influence of the $\mathrm{pH}$ of the leading electrolyte on the $\mathrm{pH}$ of the mixed zone. Leading electrolyte: $m_{L}=-77 \cdot 10^{-5}, \mathrm{pH}^{L}$ ordinate, $\mathrm{p} K_{C}=$ variable. Sample: $m_{A}=-45 \cdot 10^{-5}, \mathrm{pH}^{M}$ abscissa; $m_{B}=-30 \cdot 10^{-5}, p=1$; straight pair, $\mathrm{p} K_{A}=4.00$ and $\mathrm{p} K_{B}=4.50$; reversed pair, $\mathrm{p} K_{A}=4.50$ and $\mathrm{p} K_{\mathrm{B}}=4.00$. Variable: (a) $\mathrm{p} K_{\mathrm{c}}=2$; (b) $\mathrm{p} K_{\mathrm{c}}=3$; (c) $\mathrm{p} K_{\mathrm{c}}=4$; (d) $\mathrm{p} K_{\mathrm{C}}=5$; (e) $\mathrm{p} K_{\mathrm{c}}=6$; (d) $\mathrm{p} K_{\mathrm{c}}=$ 7. (B) Influence of the sampling ratio on the $\mathrm{pH}$ of the mixed zone. Data: as in (A), with $\mathrm{p} K_{\mathrm{C}}=4$. (a) $\varphi=\infty$ for the straight pair and $\varphi=0$ for the reversed pair; (b) $q=\infty$ for the reversed pair and $p=0$ for the straight pair.

From eqn. 20, it follows that the given pair will not separate at $\mathrm{pH}^{\mathrm{MO}}=4.52$. If a counter constituent is chosen with $\mathrm{p} K_{C}=4$, there will be no separation at $\mathrm{pH}^{L}=4.40$. Above this $\mathrm{pH}^{L}$, constituent $B$ will migrate behind $A$, whereas the order will be reversed at low $\mathrm{pH}^{L}$. It is easily shown that a low $\mathrm{pH}$ of the leading electrolyte will give a better effective mobility ratio. It should be emphasized that the influence of the mobilities of the constituents is only marginal owing to their limited numerical extension.

The influence of the sampling ratio is shown in Fig. $4 \mathrm{~b}$, where limiting values of $\gamma$ are given. At zero sampling ratio the $\mathrm{pH}$ of the "mixed" zone will be that of the isotachophoretic $A$ zone, whereas at infinite sampling ratio the $\mathrm{pH}^{M}$ will be governed by the constituent $B$. Hence, whatever the $\mathrm{pH}$ of the sample or its molar concentration ratio, the $\mathrm{pH}$ of the mixed zone will always lie between the $\mathrm{pH}$ values of the completely resolved zones. In common practice sampling ratios can show appreciable fluctuations due to the sample $\mathrm{pH}$ or the molar concentration ratio. Fig. $4 \mathrm{~b}$ therefore gives an indication of the "unsafe" margin, which in this particuiar instance extends over $0.4 \mathrm{pH}$ unit. It is obvious that the $\mathrm{pH}$ of the leading electrolyte must be chosen - well out of this "unsafe" region. Sampling ratios can show an even larger influence, when the $\mathrm{p} K$ values of the constituents show more distinct differences.

\section{Time of resolution and length of resolution}

Resolution has been defined as the separated fractional amount of the constituent under investigation. Maximal resolution, $R=1$, is obtained whenever the constituent zone contains all of the sampled amount $n$. From Fig. 3 it can be concluded that the time for resolution of the constituent $A$ can be expressed as a function of the boundary velocities $v_{L / A}$ and $v_{A / A+B}$ :

$$
t_{\text {ses }}=\frac{l_{A}}{v_{L / A}-v_{A / A+B}}
$$


Using the appropriate relationships, we obtain

$$
t_{\mathrm{res}}=\frac{n_{A} F}{I}\left(\frac{1+\varphi \cdot \frac{k_{A}}{k_{B}}}{1-\frac{\alpha_{B}^{M} r_{B}}{\alpha_{A}^{M I} r_{A}}}\right)\left(1-\frac{r_{C}}{r_{A}}\right)
$$

Hence it follows that the time of resolution is a complex function of the concentration and the $\mathrm{pH}$ of both the leading electrolyte and the sample, of the sampled amount, the sampling ratio, the electric driving current and all ionic mobilities and dissociation constants involved. It should be noted that in eqn. 31 it is the ratio of the effective mobilities and not their difference that is important. Further, this equation emphasizes the importance of the $\mathrm{pH}$ of the mixed zone.

For the length of separation compartment needed to contain the completely resolved state, $x_{\text {res }}$, it follows that

$$
x_{\mathrm{res}}=\frac{n_{A} F}{O \bar{c}_{L}^{L}}\left(\frac{1+\gamma \cdot \frac{k_{A}}{k_{B}}}{1-\frac{\alpha_{B}^{M} r_{B}}{\alpha_{A}^{M} r_{A}}}\right)\left(\frac{1}{k_{A} r_{A}}\right)=I_{A}\left(\frac{1+q^{\prime} \frac{k_{A}}{k_{B}}}{1-\frac{\alpha_{B}^{M} r_{B}}{\alpha_{A}^{M} r_{A}}}\right)
$$

where $O$ is the area of the separation compartment and $l_{A}$ is the zone length of the resolved constituent $A$.

For a given sample and electrolyte system, the resolution length is independent of the applied current density or electrical field strength, whereas the time of resolution is inversely related to the electrical driving current. From the resolution length the load capacity of the column can be deduced. Obviously, a high load capacity is always favoured by a low resolution time, so we shall confine our considerations to the resolution time.

Taking limiting values for eqn. 31 , it follows that

$$
\frac{n_{A} F}{I}<t_{\text {res }}<\infty
$$

The relationship between the sampled amount and the time of resolution is obviously linear. Moreover, for a two-constituent sample, resolution for both constituents will be obtained simultaneously. From eqns. 28 and 31 it can be concluded that both the time of resolution and the $\mathrm{pH}$ of the mixed zone are affected by the mobility of the common counter constituent. Fig. 5 shows the variation of the time of resolution as a function of the relative mobility of the counter constituent. It follows that a low $r_{c}$ value favours the time of resolution, partly because of its influence on the $\mathrm{pH}$ of the mixed zone and partly because it increases the efficiency of the current transport. The influence of the mobility of the counter constituent on the $\mathrm{pH}$ of the mixed zone is, however, marginal. For the lower limiting value of zero it follows that the $\mathrm{pH}$ of the mixed zone becomes independent of the constituent mobilities. 


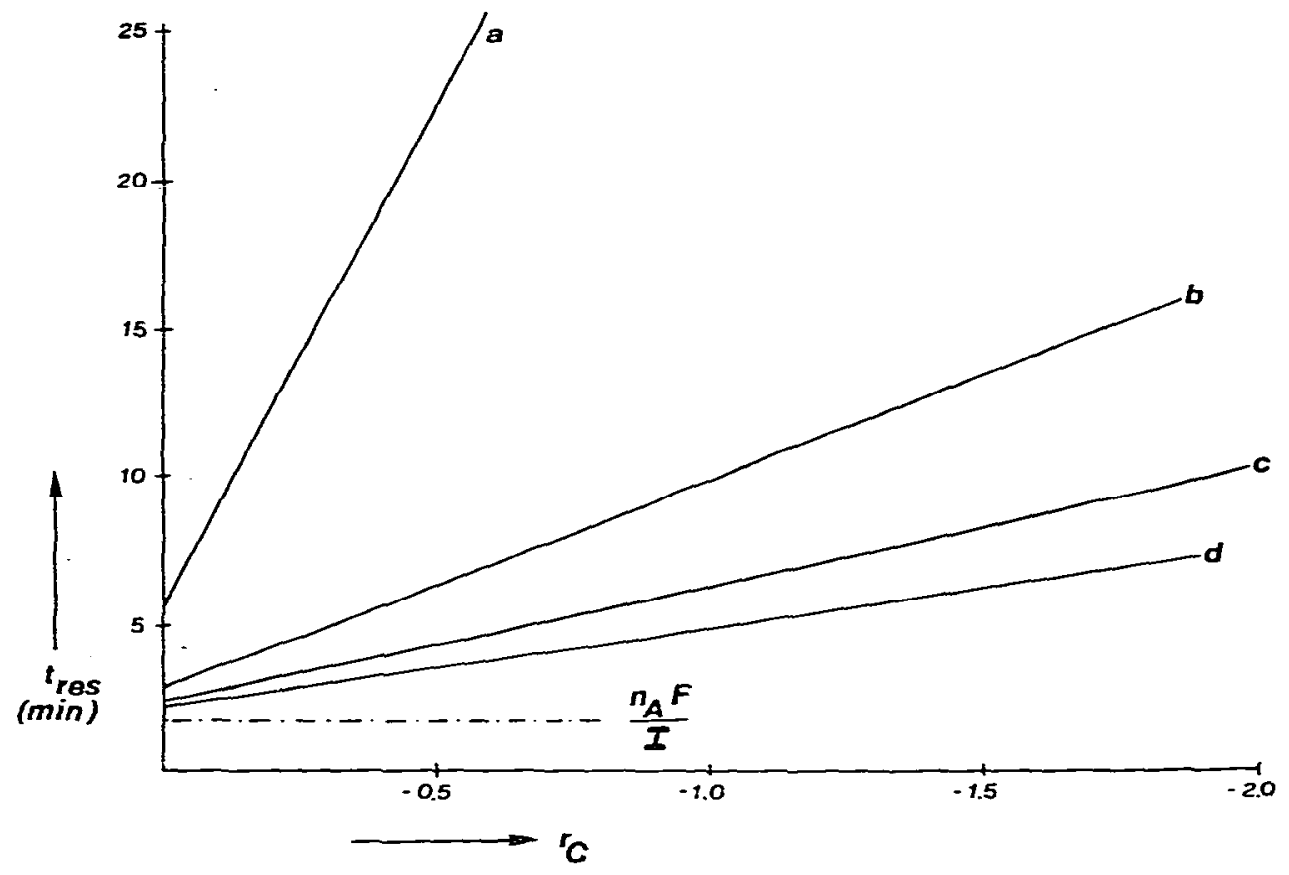

Fig. 5. Time for resolution as a function of the counter constituent mobility. Leading electrolyte: $m_{L}=-70 \cdot 10^{-5}, \mathrm{pH}^{L}=4.00, \mathrm{p} K_{L}=0 m_{C}$ ordinate, $\mathrm{p} K_{C}=4.00, \bar{c}_{L}^{L}=-0.01 \mathrm{M}$. Sample: $m_{A}=$ variable, $\mathrm{p} K_{A}=4.00, m_{B}=-30 \cdot 10^{-5}, \mathrm{p} K_{B}=5.00, \bar{c}_{A *}^{11 *}=\bar{c}_{B}^{31 * *}=0.05 \mathrm{M} . \mathrm{pH}^{1 / *}=4.00$; sample load, $n_{A}=n_{B}=10^{-7}$ mole. Driving current: $I=100 ! \mathrm{A}, O=0.002 \mathrm{~cm}^{2}$. Variable: $r_{A} / r_{B}=$ (a) 0.5 , (b) 1 , (c) 1.5 , (d) 2.0 .

As eqn. 31 is a function of the effective constituent mobilities in the mixed zone, the pH of the zone is very important. Recognizing that all mixed zone characteristics are determined by the leading electrolyte as well as by the sample, it is obvious that the relative leading concentration, $\varrho$, and the sampling ratio, $\%$, can be used in optimization procedures. Both $\gamma$ and $\varrho$ are functions of $\mathrm{pH}$ and can be chosen arbitrarily within practical limitations. In Fig. 6, the influence of the $\mathrm{pH}$ of the leading electrolyte for ionic mobilities of different species on the time of resolution is shown. The counter constituent has been chosen for its maximal buffering capacity at the $\mathrm{pH}$ of the leading electrolyte. Dealing with monovalent anionic constituents, it follows that, whenever the more mobile constituent has the higher dissociation constant (the straight pair in Fig. 6a), resolution and therefore load capacity are favoured by a low $\mathrm{pH}$ of the leading electrolyte, and vice versa for cationic constituents.

It should be noted that the effect on the time of resolution is appreciable. When the ionic mobilities are almost equal, it follows that a low $\mathrm{pH}^{L}$ must be chosen in order to obtain an acceptable time of resolution. For species that already have large differences in their ionic mobilities, the effect of decreasing the $\mathrm{pH}$ of the leading electrolyte is less pronounced. Greater differences in equilibrium constants give even higher results. The flattening of the sigmoidal curves at high $\mathrm{pH}$ indicates that the sample constituents are being separated as monovalent strong ions, in which event 

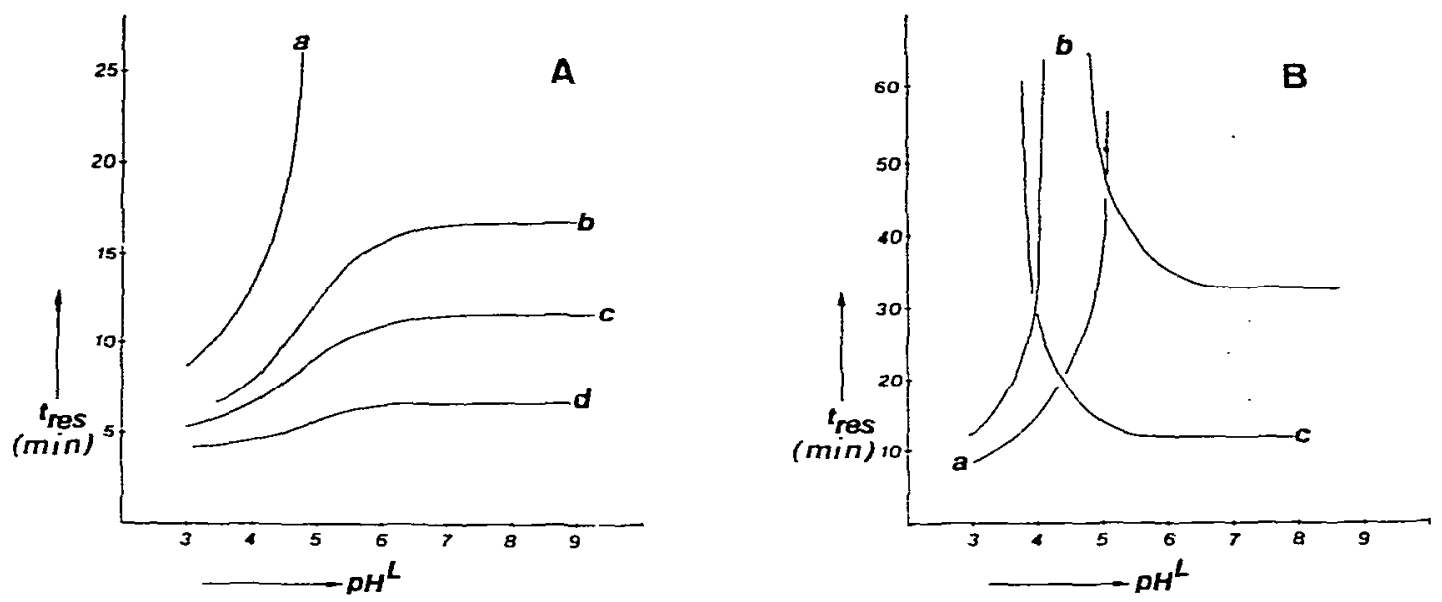

Fig. 6. Time for resolution as a function of the $\mathrm{pH}$ of the leading electrolyte. Leading electrolyte: $m_{L}=-77 \cdot 10^{-5}, \mathrm{pH}^{L}$ ordinate, $\mathrm{p} K_{L}=0, m_{C}=30 \cdot 10^{-5}, \mathrm{p} K_{C}=\mathrm{pH}^{L}, \ddot{c}_{L}^{L}=-0.01 M$. Sample: $m_{A}=$ variable, $m_{B}=-30 \cdot 10^{-5}, \bar{c}_{A}^{A *}=\bar{c}_{B}^{* * *}=-0.05 \mathrm{M}, \mathrm{pH}^{\mathrm{As} *}=4.00$; sample load, $n_{A}=n_{B}=$ $10^{-7}$ mole. (A) Straight pair; $\mathrm{p} K_{A}=4.00$ and $\mathrm{p} K_{B}=4.50$. (B) Reversed pair; $\mathrm{p} K_{A}=4.50$ and $\mathrm{p} K_{B}=$ 4.00. Driving current: $I=100 \mu \mathrm{A}, O=0.002 \mathrm{~cm}^{2}$. Variable: (A) $r_{A} / r_{B}=$ (a) 1 , (b) 1.5 , (c) 1.67 , (d) 2.0: (B) $r_{A} / r_{B}=$ (a) 1 , (b) 1.33 , (c) 2.0 .

there is, of course, no influence of $\mathrm{pH}^{L}$. If the more mobile constituent has the lower dissociation constant (the reversed pair in Fig. 6b) the situation becomes more complex. The $\mathrm{pH}$ of the mixed zone at which no separation will occur and its relation to the $\mathrm{pH}$ of the leading electrolyte have already been discussed. From Fig. 6 it follows that the $\mathrm{pH}$ of the leading electrolyte must be at least one $\mathrm{pH}$ unit different from the critical $\mathrm{pH}^{L}$ in order to obtain an acceptable time of resolution. The question of whether a high or a low pH must be chosen depends on the physico-chemical characteristics of the constituents to be separated. Nevertheless, the tendency that a low $\mathrm{pH}^{L}$ is favourable still holds. For example, when the mobility ratio is 1.33 resolution will be given at $\mathrm{pH}^{L}=7$, but a higher resolution rate will be obtained at $\mathrm{pH}^{L}=3$. At high $\mathrm{pH}$ the constituents will migrate in order of ionic mobility, whereas at low $\mathrm{pH}$ they will migrate in order of dissociation constants.

Although in practice the $\mathrm{pH}$ of the sample will show only a low degree of freedom, its influence can nevertheless be substantial. Fig. 7 shows this influence on the time of resolution as a function of the $\mathrm{pH}$ of the leading electrolyte. Again, resolution is favoured by a low sample $\mathrm{pH}$ for the separation of a straight pair. Therefore, in this instance a low $\mathrm{pH}$ of the leading electrolyte and the sample promotes the fastest separation. From Fig. 7b, where $r_{A}>r_{B}$ and $K_{A}<K_{B}$, the guidances for reversed pairs can be deduced. When running such a sample at a high $\mathrm{pH}$ of the leading electrolyte it is also preferable to use a sample with a high $\mathrm{pH}$. Optimal conditions are obtained, however, at a low $\mathrm{pH}$ of both the sample and the leading electrolyte. In both instances the arrangement of the constituents in the sampling compartment and the separation compartment will be the same. If, however, a low pH of the leading clectrolyte is combined with a high $\mathrm{pH}$ of the sample, $B$ will separate in the sampling compartment and in the separation compartment ${ }^{12}$. This phenomenon (illustrated in Fig. 8), although remarkable, has no other influence on the separation 

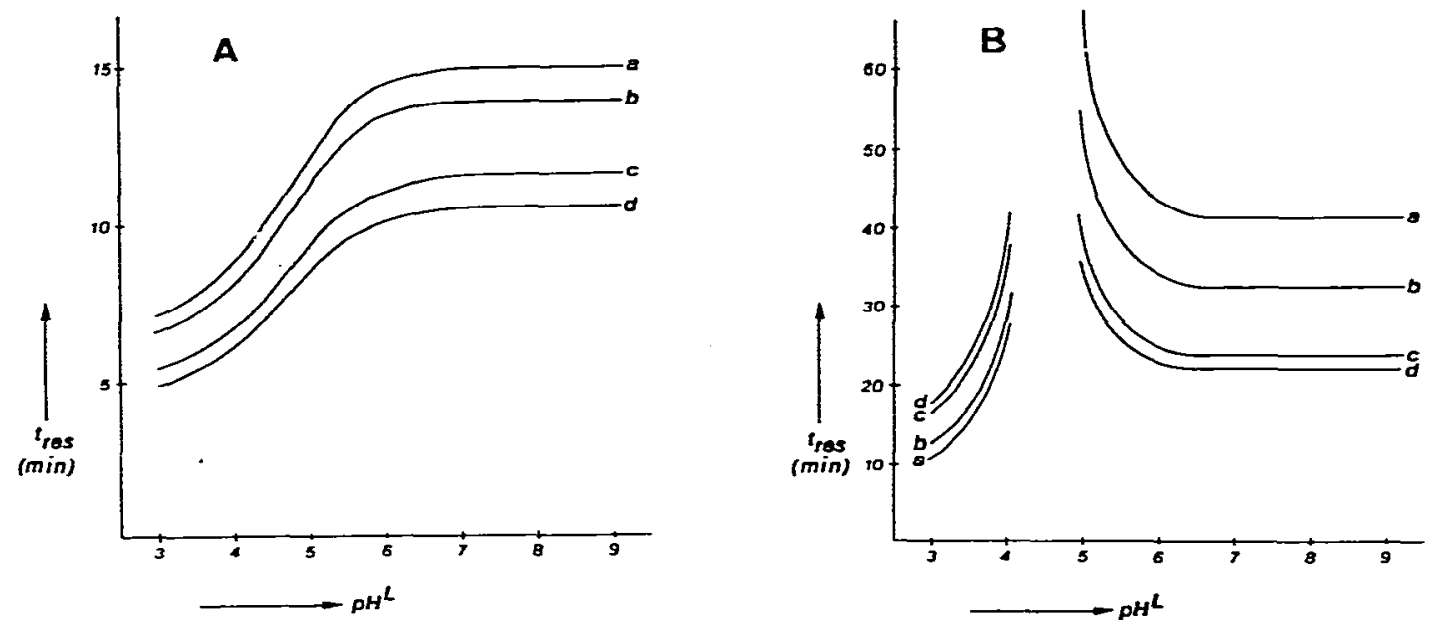

Fig. 7. Influence of sample $\mathrm{pH}$ on the resolution time. Leading electrolyte: $m_{\mathbf{L}}=-70 \cdot 10^{-5}, \mathrm{pH}^{L}$ ordinate, $\mathrm{p} K_{\mathrm{L}}=0, m_{C}=30 \cdot 10^{-5}, \mathrm{p} K_{C}=\mathrm{pH}^{L}, \bar{c}_{L}^{L}=-0.01 M$. Sample: $m_{A}=-40 \cdot 10^{-5}, m_{B}=$ $-30 \cdot 10^{-5}, \bar{c}_{A}^{M *}=\bar{c}_{B}^{M *}=-0.05 M, \mathrm{pH}^{M *}=$ variable; sample load, $n_{A}=n_{B}=10^{-7}$ mole. (A) Straight pair: $\mathrm{p} K_{A}=4.00$ and $\mathrm{p} K_{B}=4.50$. (B) Reversed pair; $\mathrm{p} K_{A}=4.50$ and $\mathrm{p} K_{B}=4.00$. Driving current: $I=100 \mu$ A, $O=0.002 \mathrm{~cm}^{2}$. Variable: (A) $\mathrm{pH}^{\mathrm{M} *}=$ (a) 8 , (b) 5 , (c) 4 , (d) 3 ; (B) $\mathrm{pH}^{\mathrm{M} *}=$ (a) 3 , (b) 4 , (c) 5 , (d) 8 .

process, as has been discussed already. Its typical behaviour will be discussed in a later paper.

From Fig. $7 \mathrm{~b}$, it follows that in the given example the $\mathrm{pH}$ of the sample has almost no influence on the critical $\mathrm{pH}^{L}$ at which a reversal of order occurs, although this need not always be the case.

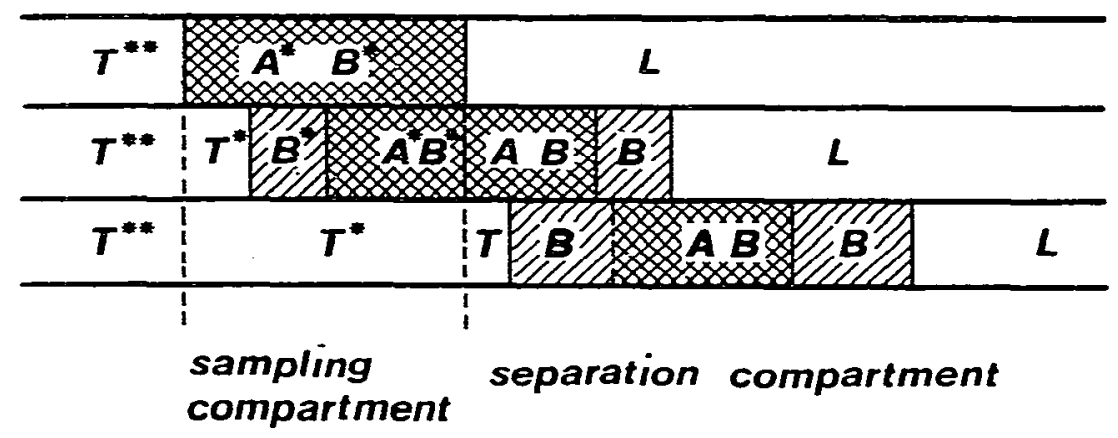

Fig. 8. The dual separation phenomenon.

\section{Resolution and resolution rate}

It follows directly from eqn. 31 that for a given sample and electrolyte system the amount of constituent $A$ resolved into its proper zone is given by

$$
n_{A}^{\text {separated }}=\frac{t I}{F}\left(\begin{array}{c}
1-\frac{c_{B}^{M} r_{B}}{\alpha_{A}^{M} r_{A}} \\
1+\varphi \cdot \frac{k_{A}}{k_{B}}
\end{array}\right)\left(1-\frac{r_{C}}{r_{A}}\right)^{-1}
$$


Thus, for the effective resolution $\bar{R}_{A}$ and its time derivative, the effective resolution rate, it follows that

$$
\bar{R}_{A}=\frac{t}{t_{\text {res }}} \text { and } \frac{\partial}{\partial t} \cdot \bar{R}_{A}=\frac{1}{t_{\text {res }}} \text {. }
$$

It must be emphasized that, owing to eqn. 30 , this resolution is an average. The actual resolution, according to eqn. 21 , can be different from the effective one, due to discontinuities in the separation process. A separation configuration causing such discontinuities is shown in Fig. 8 and the actual and effective resolution of this reversed pair is given in Fig. 9.

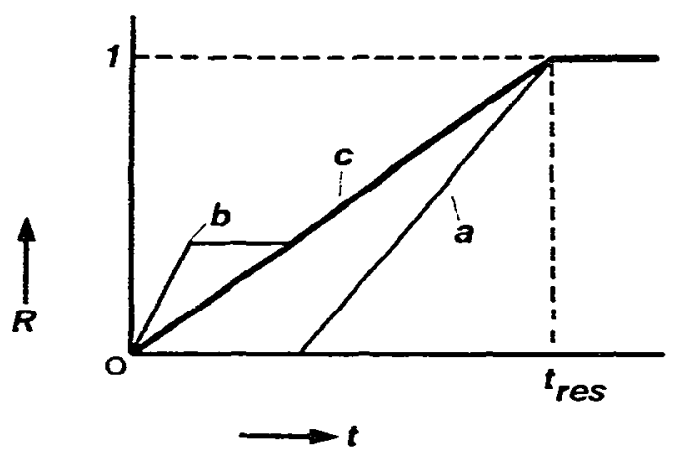

Fig. 9. The effective and the actual resolution. The separation configuration is given in Fig. 8. During some time the sample constituent $\mathcal{A}$ will not separate at all. After a definite time, however, this constituent will separate accordingly to (a); its effective resolution, however, is given by (c). The sample constituent $B$ will start to separate at a high resolution rate (b). When the sample has left the sampling compartment the resolution of the constituent $B$ will remain constant until a zone of pure $A$ is formed. The effective resolution for the constituent $B$ again is given by (c).

As a high resolution rate is always desirable, all conclusions regarding the time of resolution will apply. Eqn. 34, however, offers a unique possibility for deriving the dimensionless separation number $S$. Differentiation of the separated amount with respect to time and multiplication by $F / I$ gives

$$
S_{A}=\frac{F}{I} \cdot \frac{\partial}{\partial t} \cdot n_{A}=\left(\frac{1-\frac{\alpha_{B}^{M} r_{B}}{\alpha_{A}^{M} r_{A}}}{1+\varphi \cdot \frac{k_{B}}{k_{A}}}\right)\left(\frac{r_{A}}{r_{A}-r_{C}}\right)
$$

The advantage of this separation number is that it is essentially independent of the amount of sample, column geometry and electrical driving current. The physical significance of the dimensionless separation number is that it gives the efficiency of the separation process. Taking limiting values, it follows that

$$
0<S_{A}<1
$$


The separation number for the constituent $B$ is closely related to that of $A$, as

$$
S_{B}=\not S_{A}
$$

whiere $\chi$ is the molar concentration ratio, $\bar{c}_{B} / \bar{c}_{A}$, in the sample. The relationship between $\mathcal{X}, \varphi$ and the $\mathrm{pH}$ of the sample is straightforward ${ }^{13}$. From eqn. 36 it follows

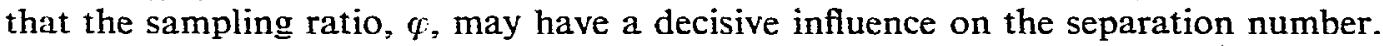
Fig. 10 shows this influence for different ionic constituents. The counter constituent has again been chosen for its maximal buffering capacity in the leading electrolyte.

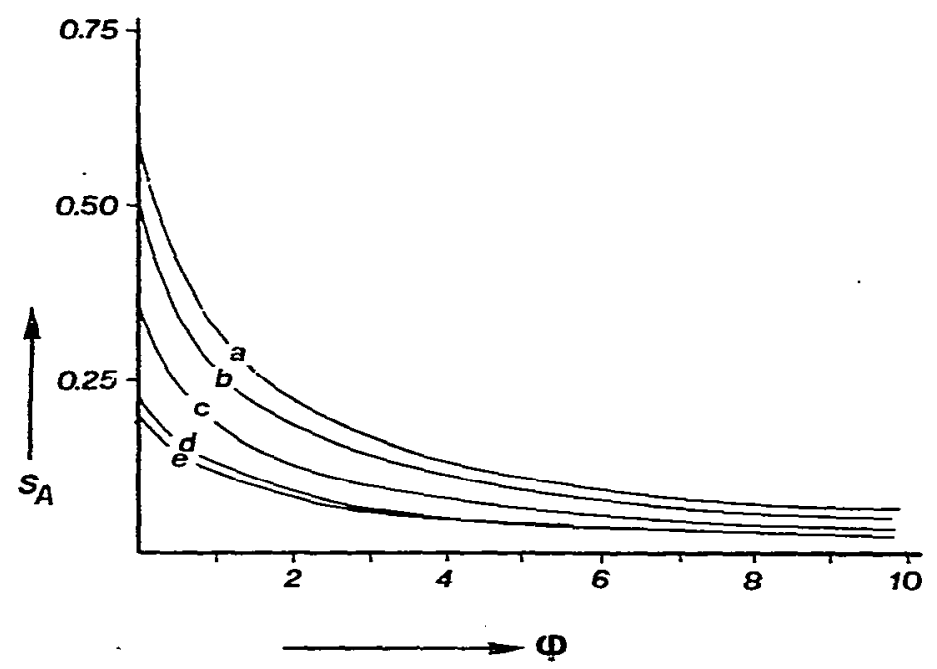

Fig. 10. Influence of the sampling ratio on the dimensionless separation number. $\varphi==$ Variable, $\underline{\varrho}=-2, r_{A}=0.6, r_{B}=0.4, r_{C}=-0.4$. (a) $\mathrm{p} K_{A}=4, \mathrm{p} K_{B}=9, \mathrm{p} K_{C}=6 ;$ or $\mathrm{p} K_{A}=\mathrm{p} K_{B}=6$, $\mathrm{p} K_{C}=4$. (b) $\mathrm{p} K_{A}=4, \mathrm{p} K_{B}=7, \mathrm{p} K_{C}=6:$ or $\mathrm{p} K_{A}=\mathrm{p} K_{B}=5, \mathrm{p} K_{C}=4$. (c) $\mathrm{p} K_{A}=4, \mathrm{p} K_{B}=6 . \mathrm{p} K_{C}$ $=6$; or $\mathrm{p} K_{A}=\mathrm{p} K_{B}=4, \mathrm{p} K_{C}=4$. (d) $\mathrm{p} K_{A}=4, \mathrm{p} K_{B}=5, \mathrm{p} K_{C}=6$; or $\mathrm{p} K_{A}=\mathrm{p} K_{B}=5, \mathrm{p} K_{C}=6$. (e) $\mathrm{p} K_{A}=4, \mathrm{p} K_{B}=4, \mathrm{p} K_{C}=6$.

It follows that the separation number decreases rapidly with increased sampling ratio. Introducing limiting values, the transport numbers ${ }^{14}$ for the constituents in their resolved zones are obtained: $S_{A}=0.6$ and $S_{B}=0.5$. Numerical calculations ${ }^{13}$ show many of the curves that are obtained when the physical parameters $\mathrm{p} K$ and $m$ are varied show congruent behaviour (Fig. 10). At low sampling ratios a large difference in $\mathrm{p} K$ values will induce a high separation number for the more mobile constituent. At high sampling ratios this effect is much less pronounced. Moreover, from curves $\mathrm{d}$ and $\mathrm{e}$ in Fig. 10 it follows that for the separation of a straight species pair a low $\mathrm{pH}$ of the leading electrolyte is favourable. It should be recognized that exact data for constituents are gencrally not known and therefore an appreciable variation in the input data has to be taken into consideration. Reasons for these variations are obvious: lack of data, unreliable data, temperature effects, activity effects, etc. The broadening effect due to the parameter fluctuations, however, is marginal ${ }^{13}$, as many of these are counter active. 
Time of detection and load capacity

Eqn. 32 suggests that a fixed-point detector must be located at $x_{\text {res }}$ from the sampling compartment. From Fig. 3, however, it follows that this is not always the case, as detection can already have commenced before the sample has been completely resolved. As the criterion for detection, only resolved constituents must be detected, i.e., the mixed zone should resolve the moment it reaches the detection system. Hence, for the minimal length at which the detector must be located, $x_{\text {det }}$, it follows that

$$
x_{\mathrm{det}}=t_{\mathrm{res}} v_{A / A B}
$$

and, for the moment at which detection must be started, $t_{\text {det }}$,

$$
t_{\mathrm{det}}=x_{\mathrm{det}} / v_{L}
$$

It follows directly that the time of resolution will be greater than or equal to the time of detection, as holds for the resolution distance and the detection distance. Using the appropriate relationships we obtain

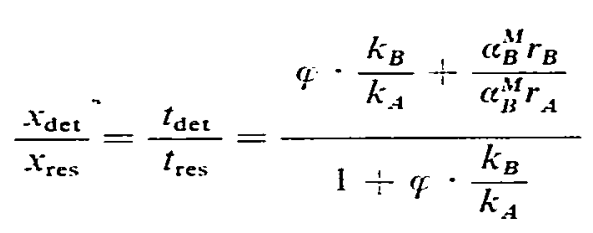

For a non-scanning detector it is important to minimize both $x_{\mathrm{det}}$ and $t_{\mathrm{det}}$, and optimization procedures are analogous to the minimization of the time of resolution. Fig. 11 shows the influence of the sampling ratio on the ratio of detection time to resolution time. As might be expected, the effect is considerable. For a low sampling ratio and low mobility ratio the time of detection will be very small compared with the time of resolution. In practical terms, this means that, whenever the more mobile sub-species has a high concentration compared with that of the less mobile subspecies, detection can be started early and only a short separation compartment is needed. At high sampling ratios, the time of detection will be equal to the time of resolution.

In common practice, however, the detector will be located at a fixed position in the separation compartment, $x_{\text {detfix }}$, so it is impossible to choose the actual length of the separation compartment. For the maximal load capacity, $n^{\max }$, for the column we obtain

$$
n_{A}^{\mathrm{max}}=n_{L}^{\mathrm{losd}} r_{A} k_{A} \cdot \frac{1-\frac{\alpha_{B}^{M} r_{B}}{\alpha_{A}^{M} r_{A}}}{q \cdot \frac{k_{A}}{k_{B}}+\frac{\alpha_{B}^{M} r_{B}}{\alpha_{A}^{M} r_{A}}}
$$

where $n_{L}^{\text {load }}$ is the amount of the leading constituent filling the separation compartment from the sampling compartment to the detector. The maximal load capacity 


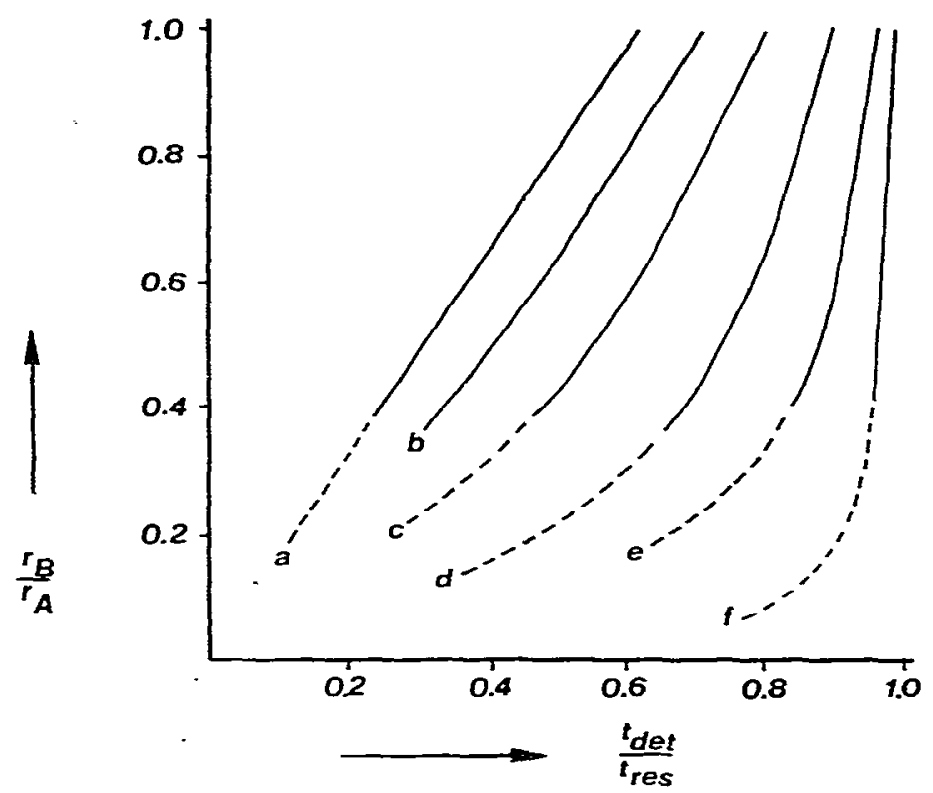

Fig. 11. Relationship between the time of detection and the time for resolution. Leading electrolyte: $m_{L}=-77 \cdot 10^{-5}, \mathrm{pH}^{L}=4, \mathrm{p} K_{\mathrm{L}}=0, m_{C}=30 \cdot 10^{-5}, \mathrm{p} K_{C}=4$. Sample: $m_{A}$ abscissa, $\mathrm{p} K_{A}=4$, $m_{B}=-30 \cdot 10^{-5}, \mathrm{p} K_{B}=4.5, \mathrm{pH}^{M *}=4, q=$ variable; sample load, $n_{A}=10^{-7}$ mole, thus $n_{B}=$ variable. Driving current: $I=100 \mu \mathrm{A}, O=0.002 \mathrm{~cm}^{2}$. Variable: sampling ratio: $\varphi=$ (a) 0.01 , (b) 0.26 , (c) 0.78 , (d) 2.33 , (e) 7.00 , (f) 21.0.

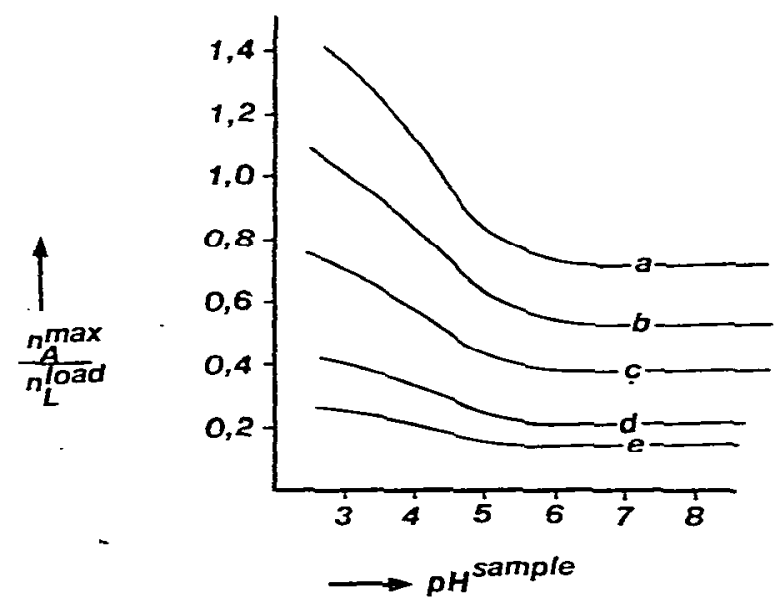

Fig. 12. Influence of the sample $\mathrm{pH}$ on the load capacity. Leading electrolyte: $m_{L}=-77 \cdot 10^{-5}$, $\mathrm{pH}^{L}=4, \mathrm{p} K_{\mathrm{L}}=0, m m_{C}=30 \cdot 10^{-i}, \mathrm{p} K_{C}=4$. Sample: $m_{A}=$ variable, $\mathrm{p} K_{A}=4, m_{B}=-30 \cdot 10^{-5}$, $\mathrm{D} K_{B}=4.5, \mathrm{pH}^{M *}$ ordinate, $n_{A}=n_{B}$. Variable: $r_{A} / r_{B}=$ (a) 2.17 , (b) 1.83 , (c) 1.50 , (d) 1.33 , (e) 1.00 .

for the second constituent follows directly from the given definitions. Moreover, eqn. 4? can be transformed directly into a time-based or distance-based form, using

$$
n_{L}^{\text {load }}=O x_{\text {detfix }} \bar{c}_{L}^{L}=t_{\text {detfix }} \cdot \frac{I}{F\left(1-r_{C}\right)}
$$


A maximal load capacity is obtained by minimizing the time for resolution. Fig. 12 shows the influence of the pH of a sample on the load capacity of a column. For this straight pair of constituents it follows that by introducing a sample at a low pH a substantial increase in load capacity can be obtained.

\section{DISCUSSION AND CONCLUSIONS}

In the transient-state model we neglected several secondary effects, e.g., temperature distribution and activity effects. Although these effects are not always marginal, they will generally not imply other guidances. With regard to uneven temperature distributions, either longitudinal or transverse ${ }^{15}$, it should be emphasized that their effect will be deleterious only under extreme operating conditions. Working at moderate current densities, without excessive cooling, convective disturbances are negligible and temperature differences can be well controlled. In special cases, temperature effects can have a favourable influence on separation but so far temperature programming has not been studied.

A fundamental question concerns the applicability of the transient-state model under extrcme $\mathrm{pH}$ valucs of the electrolytes. The hydroxyl and/or proton concentration can be introduced into the specific conductance without difficulty. It has been suggested, however, that it is not necessary to incorporate the hydrogen constituent into the moving boundary equation ${ }^{8.16}$. Neglecting the solvent effect at low or high $\mathrm{pH}$ gives differences in the zone characteristics compared with those of steady-state models ${ }^{2,8,17-19}$. The differences, however, are small ${ }^{13}$ and their experimental significance is still under investigation.

The applicability of the transient-state model and the resulting implications have been considered for a sample containing two monovalent weakly ionic constituents. The relative simplicity of the model allows a fundamental understanding of the isotachophoretic separation process and provides a realistic view of optimization procedures. It is obvious that the model could be extended to multivalent weak electrolytes. The efficiency of such considerations will be poor as no other guidances will be found. Concerning multi-component samples, it has already been mentioned that the mathematical intricacy increases rapidiy with increase in the number of constituents. For strong electrolytes extension of the model is not difficult but is laborious and monastic ${ }^{20}$ for practical purposes. The model given already indicates clearly the importance of physico-chemical and operational parameters. For multicomponent samples optimization procedures will generally be difficult, as their success depends largely on the constituents involved.

Optimal separation has been identified with a resolution of unity for the constituent of interest. As the separation boundary between two resolved zones will always have a finite interfacial thickness, in which major concentration changes will occur, the ideal resolution of unity can never be obtained. On most occasions, however, when the sharpening effect of the applied electrical field and the dispersion by diffusional and convective forces are optimized, the interfacial thickness is so small that it cannot be detected in these instances. Therefore, deviations of the resolution from unity can be neglected. For very small zone lengths $(<0.05 \mathrm{~mm})$, the interfacial thickness has a deleterious effect on resolution. Moreover, the presence of a zone profile, parabolic or otherwise, makes reliable detection of very small zones difficult, 
as not the actual zone length but the zone profile will be measured. Therefore, for accurate quantitative determinations the zone length should be reasonable.

The lower limit of resolution represents the case in which the constituent of interest does not-separate at all and therefore forms a mixed zone with another constituent. In an ideal mixed zone $\mathrm{e}^{10}$ a homogeneous concentration distribution should be present. Experimental steady-state mixed zones will have zero resolution but generally with a non-uniform concentration distribution ${ }^{21}$.

For a completely resolved sample, the resolution of all components should be unity. In practice, however, it is sufficient to obtain maximal resolution for the constituent of interest. It has been shown that for a two-constituent sample, the resolution will generally increase linearly with time. The exceptional behaviour of reversed pairs with respect to continuity and linearity has been indicated. With multicomponent systems discontinuities and non-linear behaviour will be encountered more frequently.

A maximal resolution rate is obtained when the ratio of the effective mobilities of the constituents is minimized or maximized. Very low numerical values for the effective mobilities imply high electrical gradients. The resulting temperature effects and non-electrophoretic phenomena in this instance may have deleterious effects on resolution and resolution rate. Minimization or maximization procedures naturally must fit within the constraints of the leading-terminating electrolytes. It must be emphasized that the ratio of effective mobilities from the completely resolved, i.e., steady-state, configuration gives only indirect information about the separability and separation efficiency of two constituents. Hence constituents showing virtually no difference in steady-state effective mobilities can nevertheless sometimes be separated efficiently ${ }^{12}$. In such instances the transient-state model shows that the $\mathrm{pH}$ of the mixed zone is the separation-determining parameter.

In the steady state, constituents will generally migrate in order of effective mobilities, i.e., the effective mobilities decrease from leading to terminating electrolyte. In special cases, however, a constituent with low effective mobility can migrate isotachophoretically in front of a constituent with a relatively high effective mobility. Such separation configurations have been called "enforced isotachophoresis" and are stable with respect to time? It follows that measurement of the step heights of single constituents gives only an indication of the separation configuration for a mixture of constituents. Moreover, it has been shown that, depending on $\mathrm{pH}$, constituents can migrate in a different steady-state configuration. The importance of the $\mathrm{pH}$ of the leading electrolyte in this respect has been extensively discussed. It is generally assumed that the nature of the sample, especially its $\mathrm{pH}$ and concentration, has no influence on the steady state. The transient-state model, however, reveals the importance of the $\mathrm{pH}$ of the sample. Dealing with a reversed pair of sample constituents near the critical $\mathrm{pH}$ of the leading electrolyte, at which a reversal of order can occur, the pH of the sample may, theoretically, be the deciding factor. Hence it must be concluded that the steady-state characteristics of the zone are not influenced by the $\mathrm{pH}$ of the sample, but this can affect the separation configuration. However, in practice this will not generally occur. It is obvious that, for constituents separating very slowly, it will be difficult to conclude whether the steady state has been reached or not. This holds especially for complex mixtures such as natural protein mixtures, in which the numerous constituents, each with possible microheterogeneity, may give 
rise to a continuous mobility spectrum. Such complex mixtures require a relatively long separation time. Obviously the use of spacers for such samples, whether ampholines or discrete substances, will decrease the efficiency of the separation process, but can increase the interpretability ${ }^{22}$. Whenever possible the use of discrete spacers at low concentration is to be preferred.

The critical point of separability has been expressed in the criterion for separation, i.e., the ratio of effective mobilities in the mixed state should be different from unity. It should be recognized that this criterion gives only an academic answer to the question of whether constituents can be separated or not. Dealing with separability in its limiting case, it is obvious that dispersive factors become important and should be incorporated into the equation of continuity and its resulting relationships. Relevant mathematical formulations have already been given for calculating the structure of separation boundaries in isotachophoresis ${ }^{23-25}$.

Dispersion, however, may have several causes, e.g., temperature distribution, osmotic and hydrodynamic flow and density gradients, and may exceed diffusional dispersion by several orders of magnitude ${ }^{27}$. This overall dispersion is closely related to the chosen operating conditions and the design of the equipment. Allowance can be made for such dispersive factors, but the resulting uncertainty in the criterion for separation causes this to remain academic. The model presented clearly indicates that in dealing with practical separability, other parameters are important, such as resolution, time for resolution, time of detection and load capacity. It has been shown that in addition to the physico-chemical characteristics of the constituents, the sample load, the sample ratio, the $\mathrm{pH}$ of the leading electrolyte and of the sample and the applied electrical driving current determine in practice whether resolution can be obtained within an acceptable time. For separations in which a long analysis time is needed, ultrapure electrolyte systems must be used in order to prevent a progressive decay of the steady-state configuration ${ }^{26}$. In optimization procedures three rationales can be recognized, which of course, are not completely independeat:

(i) The electrical driving current acts directly on the time of analysis. As the time for resolution is inversely related to the electrical driving current, it is obvious that this operational parameter must be maximized. In practice this will mean that a compromise must be found between the quantitative and qualitative accuracy required and the allowable driving current. The electrical driving current, if temperature effects are reglected, has no influence on the efficiency of the separation process, so the length of resolution, the location of the detection system and the load capacity are all independent of it. This is consistent with the fact that only the current-time integral is important ${ }^{7}$. In order to separate a given sample a definite number of coulombs are necessary and the time interval in which this amount must be delivered is immaterial.

When performing isotachophoretic analyses, it is therefore not necessary to work at a constant electrical driving current. Using a fixed point detector, however, a constant electrical driving current greatly facilitates the interpretation of the isotachopherograms obtained. Further, the operating conditions are more easily standarized and better controlled.

(ii) The efficiency of the current transport is directly influenced by the mobility of the common counter constituent. The favourable effect of a counter constituent with a low ionic mobility is directly reflected in the time for resolution, time for 
detection, separation number and load capacity. In practice, however, only few substances will satisfy all requirements ${ }^{2}$ : low mobility, low buffering capacity and no UV absorption.

(iii) The efficiency of the separation process is determined by the properties of the mixed zone. The transient-state model shows that these properties are also governed by the nature of the leading electrolyte as well as the nature of the sample. Considering the ratio of effective constituent mobilities in the mixed state, it follows that, owing to the limited numerical extension of ionic mobilities, $\mathrm{pH}$ or complex formation provides the best optimization parameter. In anionic separations a low $\mathrm{pH}$ of both the leading electrolyte and the sample will favour a high resolution rate and a high separation number. For cationic separations a high $\mathrm{pH}$ will be preferable.

The presence of reversed pairs of constituents may complicate the optimization procedure. In general, it can be taken that the $\mathrm{pH}$ values of the leading electrolyte and the sample should not differ too much. For known species the critical $\mathrm{pH}$ values at which separation will not occur can easily be calculated and hence can be avoided.

\section{LIST OF SYMBOLS}

\begin{tabular}{|c|c|}
\hline 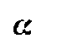 & degree of dissociation \\
\hline$A$ & constituent to be separated \\
\hline$B$ & constituent to be separated \\
\hline $\bar{c}$ & constituent concentration (mole $/ \mathrm{cm}^{3}$ ) \\
\hline$c$ & sub-species concentration (equiv. $/ \mathrm{cm}^{3}$ ) \\
\hline C & counter constituent \\
\hline$D$ & diffusional coefficient $\left(\mathrm{cm}^{2} / \mathrm{sec}\right)$ \\
\hline$E$ & electrical field strength $(\mathrm{V} / \mathrm{cm})$ \\
\hline$F$ & Faraday constant (C/equiv.) \\
\hline$i_{z} j$ & constituent, sub-species \\
\hline$J$ & electrical current density $\left(\mathrm{A} / \mathrm{cm}^{2}\right)$ \\
\hline$\kappa$ & electrical specific conductance $\left(\Omega^{-1} \cdot \mathrm{cm}^{-1}\right)$ \\
\hline$k$ & reduced mobility \\
\hline$K$ & dissociation constant \\
\hline$L$ & leading constituent \\
\hline I & zone length $(\mathrm{cm})$ \\
\hline$m$ & mobility $\left(\mathrm{cm}^{2} / \mathrm{V} \cdot \mathrm{sec}\right)$ \\
\hline $\bar{m}$ & effective mobility $\left(\mathrm{cm}^{2} / \mathrm{V} \cdot \mathrm{sec}\right)$ \\
\hline$n$ & sub-species, $A, B, C, L, T$ \\
\hline$n$ & amount of constituent (mole) \\
\hline$O$ & area $\left(\mathrm{cm}^{2}\right)$ \\
\hline pH & $\mathrm{pH}$ \\
\hline $\mathrm{p} K$ & negative logarithmic transform of $K$ \\
\hline$\varphi$ & sampling ratio \\
\hline$\chi$ & molar sampling ratio \\
\hline$r$ & relative mobility \\
\hline$R$ & resolution \\
\hline$g$ & relative leading concentration \\
\hline S & separation number \\
\hline
\end{tabular}




$\begin{array}{ll}T & \text { terminating constituent } \\ t & \text { time coordinate (sec) } \\ t_{\text {res }} & \text { time of resolution }(\mathrm{sec}) \\ t_{\text {det }} & \text { time of detection }(\mathrm{sec}) \\ t_{\text {detfix }} & \text { running time }(\mathrm{sec}) \\ v & \text { linear velocity }(\mathrm{cm} / \mathrm{sec}) \\ x & \text { place coordinate }(\mathrm{cm}) \\ x_{\text {res }} & \text { length of resolution }(\mathrm{cm}) \\ x_{\text {det }} & \text { length of detection }(\mathrm{cm}) \\ x_{\text {detfix }} & \text { running length }(\mathrm{cm})\end{array}$

Subscripts

$i, j, n \quad A, B, L, T, C$ constituent, species indicator

\author{
Superscripts \\ $K \quad A, B, L, T, M$ (mixed) zone indicators \\ ** terminating compartment \\ * sampling compartment \\ separation compartment
}

\title{
REFERENCES
}

1 F. M. Everaerts, Graduation Report, Eindhoven University of Technology, 1963.

2 F. M. Everaerts, J. L. Beckers and Th. P. E. M. Verheggen, Isotachophoresis - Theory, Instrumentation and Applications, Elsevier, Amsterdam, Oxford, New York, 1976.

3 G. Brouwer and G. A. Postema, J. Electrochem. Soc. Electrochem. Sci., 117 (1970) 874.

4 A. Tiselius, Nova Acra Regiae Soc. Sci. Ups., 4 (1930) 4 and 7.

5 H. A. Hasselbalch, Biochem. Z., 78 (1916) 112.

6 G. T Moore, J. Chromatogr., 106 (1975) 1.

7 F. Kohlrausch, Amn. Phys. Chem., 62 (1897) 14.

8 T. M. Jovin, Biochemistry, 12 (1973) 871,879 and 890.

9 R. A. Alberty, J. Aner. Chem. Soc., 72 (1950) 2361.

10 J. P. M. Wielders and F. M. Everaerts, in B. J. Radola and D. Graesslin (Editors), Electrofocusing and Isotachophoresis, Walter de Gruyter, Berlin, New York, 1977, p. 527.

11 R. Consden, A. H. Gordon and A. J. P. Martin, Biochem. J., 40 (1946) 33.

12 F. E. P. Mikkers, F. M. Everaerts and J. A. F. Peek, J. Chromatogr., 000 (1978) 000.

13 J. A. F. Peek, Graduation Report, Eindhoven University of Technology, 1977.

14 E. J. Schumacher and T. Studer, Helv. Chim. Actu, 47 (1964) 957.

15 J. O. N. Hinckley, J. Chromatogr., 109 (1975) 209.

16 H. Svenson, Acta Chem. Scand., 2 (1948) 841.

17 J. L. Beckers, Thesis, Eindhoven University of Technology, 1973.

18 R. Routs, Thesis, Eindhoven University of Technology, 1971.

19 P. Ryser, Thesis, University of Bern, 1976.

20 A. Crambach, Trends Biochem. Sci., 2 (1977) 260.

21 J. P. M. Wielders, Thesis, Eindhoven University of Technology, 1978.

22 F. E. P. Mikkers, Graduation Report, Eindhoven University of Technology, 1974.

23 J. W. Westhaver, I. Res. Nat. Bur. Stand., 38 (1947) 169.

24 A. J. P. Martin and F. M. Everaerts, Proc. Roy. Soc. London, A, 316 (1970) $49 \ddot{3}$.

25 M. Coxon and M. J. Binder, J. Chromatogr., 95 (1974) 133.

26 F. M. Everaerts, Th. P. E. M. Verheggen and F. E. P. Mikkers, J. Chromatogr., 169 (1979) in press.

27 P. B. Konstantinov and O. V. Oshurkova, Sov. Phys. Tech. Phys., 11 (1963):693. 